\title{
A Demographic Survey of GSM Subscribers' Opinion on Quality of Service: A Study of Three Towns in Edo State, Nigeria
}

\author{
Aliga P.Aliga. ${ }^{1}$, Okoro F. Moibi ${ }^{2}$, and Erimafa J.T ${ }^{3}$ \\ ${ }^{1,2}$ Department of Computer Science, Ambrose Alli University, P. M. B. 14, Ekpoma, Nigeria. \\ ${ }^{3}$ Department of Mathematics and Statistics, Ambrose Alli University, P. M. B. 14, Ekpoma, Nigeria.

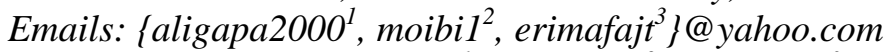 \\ Phones: $+23480\left\{56412107^{1}, 34683821^{2}, 38661434^{3}\right\}$
}

\begin{abstract}
This paper evaluated subscribers' opinion on the Quality of Service (QoS) of GSM in Edo State, Nigeria. Four major GSM operators were used for the analysis. Data were generated through questionnaire administration. Information from respondents was analysed using descriptive analysis. The results of the analysis showed that the GSM respondents were not satisfied with the QoS provided by the network operators. The implication of this is that lack of attention to the improvement of QoS by GSM service providers would significantly decrease service use by subscribers in the chosen demographic region. The paper hence, aimed at identifying QoS problems in the selected region and proffering solutions to identified problems.
\end{abstract}

Index Terms - GSM Subscribers, Service Providers, QoS, Billing System, Peak Period.

\section{INTRODUCTION}

Operators in the mobile telecommunications industry face a technical and business environment that remains in a rapid state of flux. On the business side, more than 200 million customers worldwide are demanding a broad array of services that range far beyond traditional analog/voice traffic. E-mail, faxes, files, and the Internet have become permanent fixtures in global business communications, and the extension of these services into the wireless realm is already well underway. On the technical side, operators must embrace new 2.5G technologies, such as General Packet Radio Services (GPRS) on - and prepare for the onset of 3G, which holds the promise of a global wireless standard [1].

In this continually evolving scenario, operators find themselves bracketed between their target customers, who demand a growing array of services, and their technology vendors, who supply the ultimate means of providing these services. Out of this position has come the concept of Quality of Service (QoS), which seeks to reconcile these two influences in an efficient and profitable manner.

A variety of GSM services is offered in Nigeria. [2] identified that bearer services (SMS and Fax), teleservices (voice oriented) and supplementary services (call fowarding, caller ID, call waiting) are the key services offered by Celtel, MTN, Mtel, and Globacom (GLO) - the foremost GSM operators in Nigeria. The objective of this paper was to assess QoS of GSM mobile networks as perceived by consumers under everyday conditions of use, in terms of their billing system, QoS, low network transmission, poor interconnectivity with other mobile network operators, low validity period, high cost of maintenance and their effects on subscribers.

\section{A. Quality of Service}

QoS generally refers to a measure of network performance that reflects the network's transmission quality and service availability [3]. It can come in the form of traffic policy in which the transmission rates are limited; thereby guaranteeing a certain amount of bandwidth will be available to applications [4]. QoS may also take the form of traffic shaping, which are techniques to reserve bandwidth for applications but not guarantee its availability [5].

In GSM operation, QoS refers to the probability of the telecommunication network meeting a given traffic contract or in many cases, is used informally to refer to the probability of a packet succeeding in passing between two points in the network. It essentially refers to the service quality with respect to lack of noise and tones on the circuit, appropriate handiness level, and Grade of Service (GoS). The latter comprises aspects of connection related to the capacity of a network. QoS is affected by human and technical factors. The human factors include stability of service, availability of service, delays of used information while technical factors include reliability, scalability, effectiveness, maintainability, and GoS. In network, the GoS determines the congestion experience and can results in calls being lost. It is very important that the telecommunication services provider monitors and manages the GoS of all its services to ensure that it is maintained for every origin and destination.

In essence, QoS occurs at the point of equilibrium between customer satisfaction and the reliability/performance level of a network's technical infrastructure. If either element dominates, the system is thrown out of balance and the business as a whole suffers.

\section{B. Handling Subscriber's Complaints}

A critical examination of the four GSM operators in three important towns in Edo State (Auchi, Ekpoma and Benin) show similarities in the handling of subscriber's opinion for improvement of the QoS rendered to 
subscriber. The MTN operator is examined in details in this section.

Subscribers usually make complains, by;

1) Visiting the customer-care center office;

2) Calling the customers call center number (say, 180 for MTN); or

3) Visiting the website (www.mtnonline.com)

The call-center department (which handles subscribers complains and suggestions) is headed by the Head of Department (HOD) call center. A manager is directly under the HOD. S(he) in turn controls supervisors who takes charge of call-centre agents/consultants that run a twenty-four hour shift duty to meet subscribers needs.

\section{Setbacks}

\section{1) On the subscriber}

Major problems encountered by subscribers before placing a call include inability to place a call or send SMS, inability to recharge and make balance enquiry and phone problem.

\section{2) On the GSM operators}

Issues that most GSM operators face that have, in the past years, affected the QoS are over dependence on generator for power supply, penalization or theft of communication equipment, virus affecting the computer system and under-staffing.

\section{3) On complaint instrumentality}

Visiting the customer-care center office is plagued with the shortage of manpower, aggressive nature of some subscribers, and the location of the main offices, which is currently situated only in Lagos; though plans are currently on to create more offices in various parts of the Nation.

The call center has a set-back of congestion of the network and lacks the warmth face to face conversation and a little time that is allocated to each call.

The third complaint procedure is associated with taking care of subscribers from remote locations; where they can access and query the website at their own convenient time. More than one subscriber can be attended to, at the same time without being placed on queue. The set-back is the non-availability of internet services in all parts of the nation and the high cost of designing and maintaining a website.

\section{Materials AND Methods}

A survey of GSM mobile network performance in the cities of Auchi, Ekpoma and Benin was undertaken in the period from 15/01/2007 to 30/3/2007. Data collection took place on working days, during normal working/academic hours, between these periods. About 2350 contacts were made, corresponding to about 116 hours 15 minutes of measurements along 6 kilometres each across these higher-institution towns. These higherinstitution towns were chosen because the highest numbers of GSM users in Edo State, Nigeria are found mostly in the towns. The quality of GSM Mobile Service provided to the public in general by the operators Celtel, MTN, Mtel and GLO was verified.

The methodology was enabled on-the-ground verification of Quality of Service, providing a picture of network performance from the user standpoint that was as realistic as possible. In accordance with the guidelines, the targeted operators were not informed that the study was being carried out.

Considering the users' subjective views themselves, it is impossible to rigorously reproduce each consumer's conditions of interaction with the networks. The results of this study must thus be understood as an indicator of the networks' behaviour. Their transposition/extrapolation to specific situations requires some prudence, at the risk that biased conclusions might be taken.

\section{A. Research Design}

The population of the study consisted basically of 2350 mobile phone users which consist of workers, traders and students subscribing the GSM network services in Auchi, Ekpoma and Benin, Edo State.

\section{B. Research Instrument}

The research instrument, designed to suit the purpose of the survey, was a structured, self-constructed questionnaire titled "Statistical Analysis of GSM Subscribers' Opinion on Quality of Service in Edo State, Nigeria (SAGSOQoS)”. Questionnaires are appropriate for gathering the views of a large number of people about a particular phenomenon [6]. Two thousand three hundred and fifty questionnaires were administered on 2350 respondents. The instrument solicits information on their opinion towards the GSM network services and the problem encountered during the course of assessing the network service. It contains two sections. Section A seeks information on personal data of respondents such as age, sex, marital status etc. Section B contains 20 questions requiring information from respondents on the general knowledge, accessibility, continuity and conformity of GSM network service. Overall, 1395 properly completed questionnaires, representing a response rate of $59.36 \%$, provided quantitative data. This response rate is adjudged by [7] to be very good. Only about $40.64 \%$ declined.

\section{Statistical Analysis}

Results were expressed as descriptive statistics (frequencies, percentages and charts) and analysed using SPSS for Windows (version 11.0).

\section{Instrument Administration}

All interviews were conducted by the authors through the research instrument, and lasted approximately 5 minutes for each administration. All demographic data, including socio-economic status, were collected from the subject. 


\section{RESULTS}

\section{A. Presentation of Data and Analysis}

The presentation of personal data of respondents was first analyzed. This was followed by main response to general question asked on the mobile phone users, on the opinion of the services provided by the GSM operators located in Auchi, Ekpoma and Benin. Simple descriptive statistics were employed for data analysis.

\section{B. Demographic Analysis}

1) Network Significant Relationships Among Chosen Towns

Demographic data for the network variables among selected towns is presented in the Fig 1. Subjects used mostly GLO ( $n=537,38.5 \%)$ across the demographic region. There was no significant difference between the network variables with regard to the demographic makeup of the study sample in each town, since they represented similar pattern of population. However, it was observed that MTN $(n=428,30.7 \%)$ and GLO collectively had higher socio-economic status than CELTEL ( $n=307,22.0 \%)$ and MTEL ( $n=123,8.8 \%)$. Also, half of the subscribers $(n=728,52.2)$ were located in Benin with MTN ( $\mathrm{n}=254)$ network dominating the group. Overall, MTEL in Auchi had the least subscribers $(n=11)$.

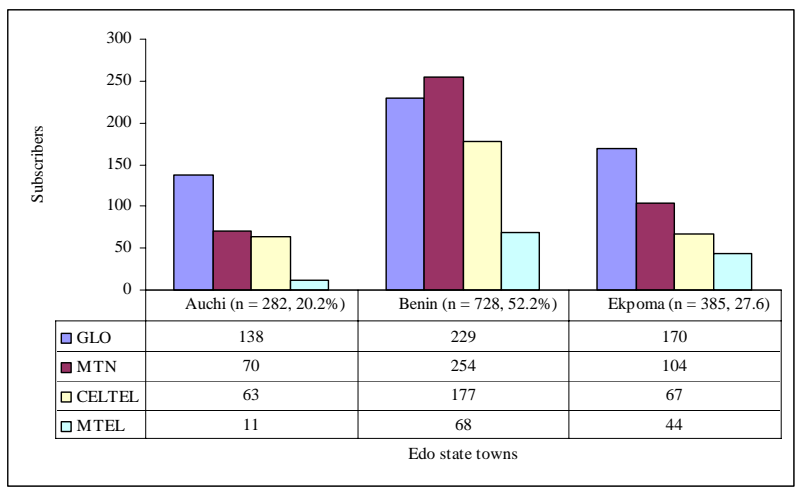

Fig. 1 A multiple bar chart showing demographic variables of selected networks among towns.

\section{2) Gender and Age}

More subjects agreed to participate during the control weeks and thus there was an unequal group size (see Table 1). Age ranged from 20 to 70 with a mean average of 48 years. Greater than $60 \%$ of the subjects were $20-40$ years of age. It is noteworthy that females dominated $(n=783,56.1 \%)$ and were mostly between $20-30$ years $(n=371,26.6 \%)$. The least participants $(n=14,1 \%)$ were males and fell within the age bracket $61-70$. The most prevalent age group was $20-30$ with a $51.7 \%(n=721)$ rate.
TABLE 1

DEMOGRAPHIC VARIABLES OF GENDER AND AGE

\begin{tabular}{ccccccc}
\hline \hline $\begin{array}{c}\text { Age bracket } \\
\text { (in years) }\end{array}$ & $\begin{array}{c}\text { All male } \\
\text { population } \\
\text { \% }\end{array}$ & $\begin{array}{c}\text { All female } \\
\text { population } \\
\text { \% }\end{array}$ & \multicolumn{2}{c}{ Total } & \% \\
\hline $20-30$ & 350 & 57.2 & 371 & 47.4 & 721 & 51.7 \\
$31-40$ & 146 & 23.9 & 266 & 34 & 412 & 29.5 \\
$41-50$ & 65 & 10.6 & 91 & 11.6 & 156 & 11.2 \\
$51-60$ & 37 & 6 & 29 & 3.7 & 66 & 4.7 \\
$61-70$ & 14 & 2.3 & 26 & 3.3 & 40 & 2.9 \\
TOTAL & 612 & 100.0 & 783 & 100.0 & 1395 & 100.0 \\
\hline
\end{tabular}

3) Network Quality and Recharging Power

The collective response to subscribers' views on network quality and power of recharging account across the demographic area is summarised in Fig. 2. It was observed that $51.8 \%(n=723)$ of the subjects complained of poor network quality against $39.3 \%(n=548)$ and $8.9 \%$ $(n=124)$ who claimed that the network was good and excellent respectively. As a result, only 69 (4.9\%) subjects who complained of poor network quality were able to recharge their accounts daily, even though most subscribers $(n=675,48.4 \%)$ recharge weekly. It was amazing to note that $17(1.2 \%)$ subjects with the opinion of excellent performance were able to recharge monthly. However, there was no significant difference between those who recharge daily $(n=53,3.8 \%)$ and weekly ( $n=54,3.9 \%$ ), and claim excellent network performance, giving some confidence that they represented the same population.

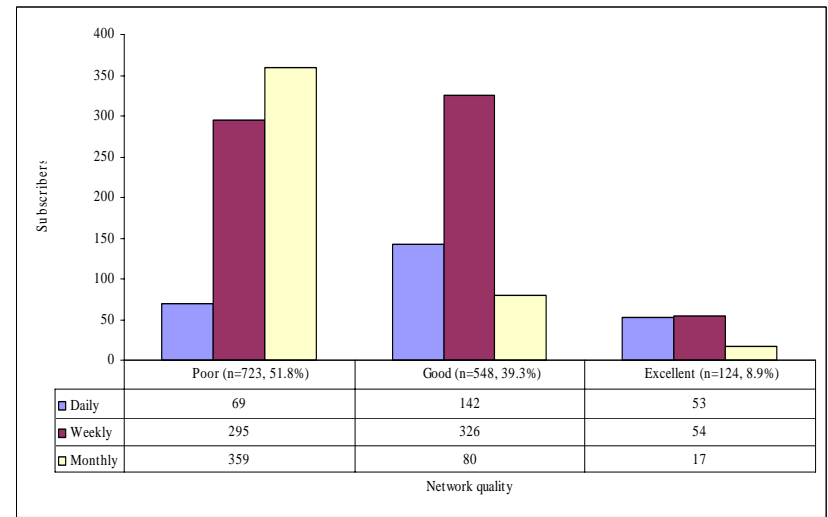

Fig. 2 A multiple bar chart showing demographic variables of network quality and power of recharging account.

\section{4) Level of Income and Recharging Power}

The analysis from table 2 confirmed that $48.4 \%$ $(n=675)$ of the subjects bought recharge cards weekly in their mobile phone, while $32.7 \%(n=456)$ did so on a monthly basis. Of these subjects only $18.9 \% \quad(n=264)$ recharged their accounts on a daily basis. It is reasonable to note that most participants whose income fall within \#7,500-\$14,999 ( $n=412)$ recharge their accounts monthly, while most income earner within $\$ 15,000$ \#34,999 recharged weekly. It is however amazing to observe that out of the 1395 subjects only $14 \%(n=195)$ of those that fall within $\$ 35,000$-Above recharged their 
accounts, whereas over 52\% $(n=727)$ of GSM users fell within $\$ 7,500-\$ 14,999$ income level. Only 4 out of 473 whose income level fall within $\$ 15,000-\$ 34,999$, recharged monthly.

TABLE 2

DEMOGRAPHIC VARIABLES OF INCOME LEVEL AND POWER OF RECHARGING ACCOUNT

\begin{tabular}{cccccc}
\hline \multicolumn{5}{c}{ RECHARGING ACCOUNT } \\
\hline \hline $\begin{array}{c}\text { Income Level } \\
\text { (in \#) }\end{array}$ & \multicolumn{2}{c}{ Power of Recharging Account } & \multicolumn{2}{c}{ Total } \\
& Daily & Weekly & Monthly & & $\%$ \\
\hline $7,500-14,999$ & 52 & 263 & 412 & 727 & 52.1 \\
$15,000-4,999$ & 112 & 357 & 4 & 473 & 33.9 \\
$35,000-$ Above & 100 & 55 & 40 & 195 & 14.0 \\
Total & 264 & 675 & 456 & 1395 & 100.0 \\
\hline
\end{tabular}

5) Network Quality and Level of Income

It was observed that most subscribers whose level of income fell within $\$ 7,500-\$ 14,999 \quad(n=535,38.4 \%)$ complained of poor network quality (see Fig. 3). respondents whose income falls within $\$ 35,000$-Above $(n=55,3.9 \%)$ were most of the opinion of excellent quality of network. However, about $33.9 \%(n=473)$ of the subjects fall within income level of $\$ 15,000-\$ 34,999$.

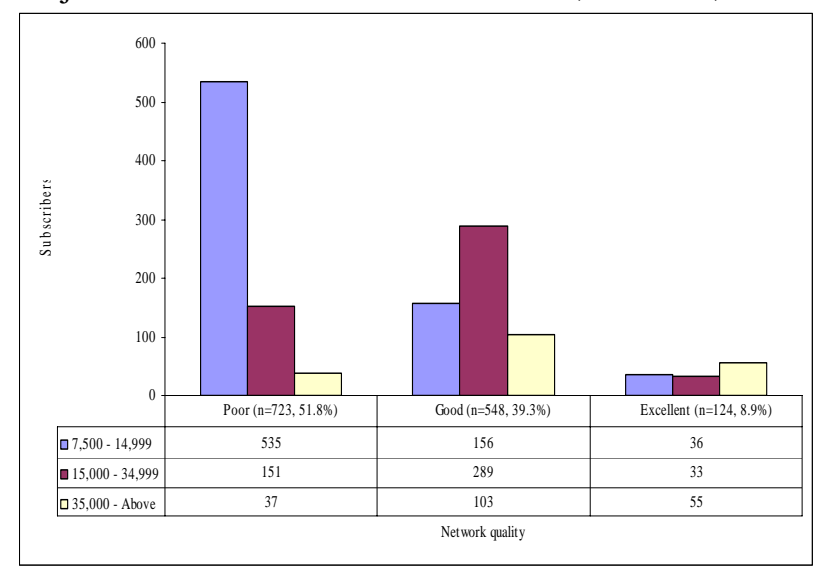

Fig. 3 A multiple bar chart showing demographic variables of network quality and level of income.

6) Recharging Power and Billing Preference

Within the participating cohort, the relationship between billing preferences and recharging power of subscribers was investigated (see Table 3). As identified, only two (0.1\%) subjects that subscribe to per-minute billing recharge their accounts daily. Most participants ( $n=675,48.4 \%$ ) recharged their accounts weekly, especially those who subscribe to per-second $(n=648$, $46.5 \%$ ) billing. Again, majority of the subjects subscribed to per-second $(\mathrm{n}=1302,93.3 \%)$ billing (PSB), whilst 6 who are on per-minute billing (PMB) recharge daily. Only 2 out of 264 participants that were on PMB recharged daily.
TABLE 3

DEMOGRAPHIC VARIABLES OF RECHARgING POWER AND BILLING PREFERENCE

\begin{tabular}{ccccc}
\hline \hline $\begin{array}{c}\text { Power of } \\
\text { Recharging } \\
\text { Account }\end{array}$ & \multicolumn{2}{c}{ Billing Preference } & \multicolumn{2}{c}{ Total } \\
\hline Daily & 262 & 2 & 264 & 18.9 \\
Weekly & 648 & 27 & 675 & 48.4 \\
Monthly & 392 & 64 & 456 & 32.7 \\
Total & 1302 & 93 & 1395 & 100.0 \\
\hline
\end{tabular}

\section{DISCUSSION}

The results from the survey indicated that high percentage of the students use the selected networks. It suggests that these students are knowledgeable at least to some extent in the use of GSM networks. Also this proficiency indicates the importance that availability and regular use of GSM networks plays in learning. Evaluation results obtained revealed that half of the subjects complained of poor network quality. This is not encouraging. The results correlate with the findings of [2], [8] and [9]. [2] and [8] attributed this problem to the palpable oversubscription compared to available facilities of the selected GSM networks, network congestion, and static switching capacity. The GSM operators should, as a result, concentrate on network expansion as recognised by Chris. GLO for instance has added 0807 to their network, while MTN has added 0806 and 0703 to its network. Celtel [formally called Econet, Vodacom and Vmobile] has added 0808 to its network.

Of particular interest, is the evidence that almost half of the subjects buy recharge cards weekly in their mobile phones. Moreover, more than half of the subscribers who recharge their accounts (mostly monthly) were lowincome earners, while a few high-income earners in the study recharge their accounts, and mostly on a daily basis. This can be attributed to the fact that respondents were mostly students and workers with low income levels who find GSM networks rather useful but could not afford to recharge more frequently. This could suggest why they prefer recharging weekly and monthly, and do most of their calls at call/business centres [2]. The results from the survey show that there are more PSB subscribers than PMB subscribers. The PMB is such that even if the call is cleared after ten seconds, the subscriber is still charged for the remaining time left. This explains the results from this study.

Based on our case study and the presented previous case studies, we can conclude that the QoS should be improved, because as the mobile service is expanding, subscribers expect more than just speed. Subscribers demand a total solution that will meet their diverse needs and looking for networks that are optimized to handle corporate wireless applications.

Key strategies to consider overcoming these barriers include:-

a. A downward review of tariff (taxes) charged 
by the GSM operators(especially Celtel, MTN, Globacom and Mtel) in the country;

b. Reduction of airtime utility, charged on every call made by subscribers;

c. Building of more transmission and base stations in strategic places, in order to boost network reception in every part of the town. This will reduce teledensity within network.

d. An improvement on GSM operators operating facilities. This would be done by upgrading the systems so as to accommodate more services as well as automate their system interconnectivity with other communication service providers for automatic roaming and information linkage.

\section{CONCLUSION}

This study provided a first attempt at classifying QoS opinion from the standpoint of GSM subscribers from Edo State, Nigeria and correlating these views with the extant literature and suggesting strategies to manage and overcome them. The results showed that the GSM respondents are not satisfied with the QoS provided by the network operators. Many mobile phone users do not have satisfactory usage of the telephone services. Subscribers complained of call-drop during telephoning, low voice quality, poor interconnectivity, high billing system on services provided and poor reception to network service problems. The greatest worries and drawbacks of the GSM network service is the cost of maintenance, access day-to-calls validity are short, problems of teledensity (i.e. network congestion) in the areas covered by service operators. The billing system has evolved from PMB to PSB system. It would therefore seem reasonable to consider the strategies mentioned above.

Survey limitations include survey size and lack of testing and measurement equipment such as indicators [like M366plus ${ }^{1}$, a QoS analyser for GSM networks] for measuring network accessibility and audio quality from base stations. It also lacked post-processing tools [like Report software that is associated to the M366plus], which stores, organises and generates statistics from the information previously collected by the measurement units. The survey only relied on subscribers' information, instead of also weighing the credibility of the networks from their base stations.

Further research should be based on network performance from the stations using these instruments. Moreover, targeted operators should not be informed before arrival at the base stations to avoid tiding up their shortcomings before testing, measurements and postprocessing, and hence defeat the purpose of the study. A

\footnotetext{
${ }^{1}$ The M366plus equipment includes a GPS receiver that enables georeferencing for all of the measurements made. This information is handled by the "GeoReport" tool which, in parallel with a third tool "MAPINFO" - enables viewing of the statistical information generated by "REPORT", on digital geographical charts [4].
}

comprehensive study of QoS from subscribers and base stations would go a long way in finding an acceptable balance between customer satisfaction and the performance level of network infrastructure.

Lastly, the results of this study could be of specific interest in communications establishments, educational institutions and those that want to take on further research with the study.

\section{REFERENCES}

[1] Tektronix, "Quality of Service for the Mobile Network Operator", Tektronix Communications Test. 2006. Available: http://www.tek.com

[2] P. A. Aliga, C. U. Onianwa and F. I. Sadiq, "GSM: The Economic Implications in Nigeria”, 7th International Conference Proceedings of the Nigeria Computer Society (Formerly COAN), Volume 14, No. 1, June 17-20, 2003, Abuja, Nigeria.

[3] Wireless Glosary, 2006

Available: http://www.devx.com/wireless/Door/11448

[4] ANACOM, "GSM Mobile Networks: Quality of Service Survey". 2005. Available: http://www.anacom.pt/template12.jsp?categoryId=186283

[5] ANACOM, "GSM Mobile Networks - Quality of Service Survey: Lisbon, Oporto and A1”. 2002. Available: http://www.anacom.pt/template15.jsp?categoryId=49293

[6] M. Stroh, “Qualitative interviewing”, In D., Burton (ed.) Research Training for Social Scientists: A Handbook for Postgraduate Researchers. Sage Publications, 2000, London:.

[7] E. Babie, "The Practice of Social Research", 5 ${ }^{\text {th }}$ ed., Wadsworth Publishing, 1989, Belmont, CA.

[8] T. Abimbola, "All is Set for Tremendous Expansion", IT and Telecoms 2003, Infotech, Financial Standard, Jan. 2003.

[9] A. Chris, "GSM: Half-Year Verdict”, Newswatch (Lagos), Volume 35 No 6, Feb. 2002. Available: http://allafrica.com/sendpage.html?ref=http://allafrica.com/ stories/200202200698.html.

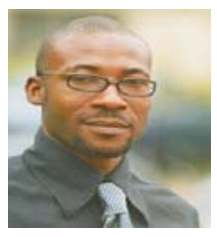

Aliga Paul Aliga, is a Lecturer in Computer Science Department at Ambrose Alli University (AAU), Ekpoma, Nigeria. He received his B.Tech (1997) in Mathematics and Computer Science from Federal University of Technology Owerri (FUTO), Nigeria, his M.Sc. (2002) in Computer Science from Nnamdi Azikiwe University (NAU), Awka, Nigeria: where he is currently a PhD student in Computer Science. Aliga is a member of the Nigeria Computer Society (NCS). His research interests include ICTs, neural networks, and web \& mobile technologies. He has published in these areas.

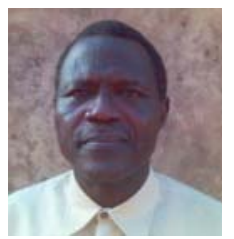

Okoro, Felix Moibi, is currently a Senior Lecturer in Computer Science Department at Ambrose Alli University (AAU), Ekpoma, Nigeria. He obtained B.Sc., MSc. (Ed) (Western Oregon), M.Sc., PhD (Ilorin). His research interests include scientific computing, numerical computation of ordinary differential equations and software engineering. He is a member of the Society for Industrial and Applied Mathematics (SIAM), USA and the Association of Computing Machinery (ACM), USA.

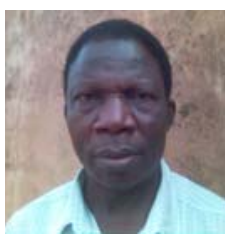

Erimafa John Tunde, is a Senior Lecturer in Mathematics and Statistics Department at Ambrose Alli University (AAU), Ekpoma, Nigeria. He obtained B.Sc. / M.Sc. (1974), and PhD (1979) in Moscow State University. His research interests include, statistical inference and data mining. He is a member of the Mathematical Association of Nigeria (MAN), and the Statistical Association of Nigeria (SAN). 